\title{
Towards Finding More Diagnostic Serological Markers in Celiac Disease: Can Deamidated Gliadin Peptide Antibodies Help to Our Babies?
}

\author{
Nur Arslan* \\ Dokuz Eylul University Faculty of Medicine, Department of Pediatrics, Division of Pediatric Gastroenterology, Hepatology and \\ Nutrition, Izmir, TURKEY
}

Celiac disease (CD) is a common immune-mediated enteropathy triggered by gluten in genetically susceptible individuals with an overall prevalence almost $1 \%$ in different countries [1]. The diagnosis of the disease is classically based on a combination of serologic tests and characteristic intestinal biopsy findings [2]. In a recent meta-analysis performed by European Society of Pediatric Gastroenterology, Hepatology and Nutrition (ESPGHAN) Working Group of Celiac Disease Diagnosis, 16 studies have been reviewed and anti-antiendomysial (EmA) and anti-tissue transglutaminase (tTG) IgA antibodies have been found more accurate tests for the diagnosis of CD [2]. In this meta-analysis, their sensitivities have been detected more than $90 \%$, and specifities have been found $98.2 \%$ for anti-EmA and $\geq 90 \%$ for anti-tTG [2].

With the improvement of serological tests, diagnosis of CD without intestinal biopsies has been suggested in some defined situations [3]. On the other hand, despite the high diagnostic performance of anti-tTG and anti-EmA antibodies for CD, they have lower accuracy in children younger than 2 years of age and patients with selective IgA-deficiency [4]. ESPGHAN Working Group of CD Diagnosis prepared new guidelines for $C D$ diagnosis in 2012 [5]. According to these criteria, diagnosis is based on the combined evaluation of symptoms, serological tests, biopsy findings, and human leukocyte antigen (HLA) typing [5]. In symptomatic patients who have anti-tTG titers $>10$ times the upper limit of normal and positivity for EmA, it is possible to diagnose CD without performing the intestinal biopsy [5]. It has been proposed that, for patients with IgA deficiency the decision should be made from the results of the IgG class antibody tests [5]. Typing of HLA-DQ2 and HLA-DQ8 is a useful tool, which has a diagnostic sensitivity of $>96 \%$. Therefore, a negative result of HLA-DQ2 and/or DQ8 testing makes a diagnosis of CD highly unlikely [5,6].

Recent studies showed that anti-deamidated gliadin peptide (DGP) antibodies had higher sensitivity and specificity than conventional anti-gliadin antibodies [7], consequently anti-DGP antibodies joined anti-tTG and anti-EmA as tests with high diagnostic performance $[8,9,10]$. On the other hand, some studies demonstrated superior diagnostic value of anti-tTG to anti-DGP antibodies even in patients younger than 2 years-old [11]. In this first issue of the Journal, Oana et al [12] investigated the accuracy of these antibodies in symptomatic infants. They evaluated the diagnostic value of combined IgA/IgG DGP/tTG screen assay in anti-IgA

tTG or anti-EmA negative children younger than 2 yearsold. All children had normal total IgA concentration and were consuming gluten at the time of the study. Diagnosis of celiac disease was made according to intestinal biopsy findings. They found the sensitivity of combined IgA/IgG DGP/tTG screen assay (95.4\%) higher than both antitTGA (86.3\%) and anti-EmA (91\%) antibodies in this age group of children [12]. They concluded that better performance of this combined tests might preclude repeated intestinal biopsies in young symptomatic children who have negative tTG/EmA serology. Recent ESPGHAN guideline also proposes that anti-DGP antibodies may be used as additional tests in patients who are negative for other celiac spesific antibodies but have symptoms compatible with celiac disease, especially in patients younger than 2 years-old [5].

In conclusion, intestinal biopsy is an invasive diagnostic method especially in young children. Further more sensitive serological tests can provide the definite diagnosis of celiac disease especially in younger age group without this invasive procedure.

\section{References}

[1] Dubé C, Rostom A, Sy R, Cranney A, Saloojee N, Garritty C, Sampson M, Zhang L, Yazdi F, Mamaladze V, Pan I, Macneil J, Mack D, Patel D, Moher D. The prevalence of celiac disease in average-risk and at-risk Western European populations: a systematic review. Gastroenterology 2005;128(4 Suppl 1):S57-67.

[2] Giersiepen K, Lelgemann M, Stuhldreher N, Ronfani L, Husby S, Koletzko S, Korponay-Szabó IR; ESPGHAN Working Group on Coeliac Disease Diagnosis. Accuracy of diagnostic antibody tests for coeliac disease in children: summary of an evidence report. $\mathrm{J}$ Pediatr Gastroenterol Nutr 2012; 54:229-241.

[3] Hill PG, Holmes GK. Coeliac disease: a biopsy is not always necessary for diagnosis. Aliment Pharmacol Ther 2008; 27:572577.

[4] Lefter DA, Schuppan D. Update on serologic testing in celiac disease. Am J Gastroenterol 2010; 105:2520-2524.

[5] Husby S, Koletzko S, Korponay-Szabó IR, Mearin ML, Phillips A, Shamir R, Troncone R, Giersiepen K, Branski D, Catassi C, Lelgeman M, Mäki M, Ribes-Koninckx C, Ventura A, Zimmer KP; ESPGHAN Working Group on Coeliac Disease Diagnosis; ESPGHAN Gastroenterology Committee; European Society for Pediatric Gastroenterology, Hepatology, and Nutrition. European Society for Pediatric Gastroenterology, Hepatology, and Nutrition guidelines for the diagnosis of coeliac disease. J Pediatr Gastroenterol Nutr 2012; 54:136-160.

[6] Margaritte-Jeannin P, Babron MC, Bourgey M, Louka AS, Clot F, Percopo S, Coto I, Hugot JP, Ascher H, Sollid LM, Greco L, Clerget-Darpoux F. HLA-DQ relative risks for coeliac disease in 
European populations: a study of the European Genetics Cluster on Coeliac Disease. Tissue Antigens 2004; 63:562-567.

[7] Prause C, Ritter M, Probst C, Daehnrich C, Schlumberger W, Komorowski L, Lieske R, Richter T, Hauer AC, Stern M, Uhlig $\mathrm{HH}$, Laass MW, Zimmer KP, Mothes T. Antibodies against deamidated gliadin as new and accurate biomarkers of childhood coeliac disease. J Pediatr Gastroenterol Nutr 2009; 49:52-58.

[8] Hope BC, Ameratunga R, Austin PM, Evans HM, MacFarlane J, Mouat S, Chin SE. Diagnostic utility of modified gliadin peptide antibody assays in New Zealand children. J Pediatr Gastroenterol Nutr 2013; 57:43-48.

[9] Amarri S, Alvisi P, De Giorgio R, Gelli MC, Cicola R, Tovoli F, Sassatelli R, Caio G, Volta U. Antibodies to deamidated gliadin peptides: an accurate predictor of coeliac disease in infancy. J Clin Immunol 2013; 33:1027-1030.
[10] Blesa-Baviera LC, Donat Aliaga E, Ortigosa L, Litwin N, PeñaQuintana L, Méndez V, González MV, López-Manzanares JM, Méndez E, Koninckx CR. Celiac disease screening by immunochromatographic visual assays: results of a multicenter study. J Pediatr Gastroenterol Nutr 2007; 45:546-550.

[11] Olen O, Gudjónsdóttir AH, Browaldh L, Hessami M, Elvin K, Liedberg AS, Neovius M, Grahnquist L. Antibodies against deamidated gliadin peptides and tissue transglutaminase for diagnosis of pediatric celiac disease. J Pediatr Gastroenterol Nutr 2012; 55:695-700.

[12] Oana B, Otilia M. The usefulness of IgA/IgG DGP/tTG screen assay for celiac disease detection among symptomatic and at risk young children. Int J Celiac Dis 2013; 1:23-26. 